\title{
Cytogenetic Characteristics of New Monosomic Stocks of Cotton (Gossypium hirsutum L.)
}

\author{
Marina F. Sanamyan, ${ }^{1}$ Julia E. Petlyakova, ${ }^{1}$ Elnora A. Sharipova, ${ }^{1}$ \\ and Ibrokhim Y. Abdurakhmonov ${ }^{2}$ \\ ${ }^{1}$ Cotton Genetics Laboratory, National University of Uzbekistan, Tashkent, Vuzgorodok 100174, Uzbekistan \\ ${ }^{2}$ Center of Genomic Technologies, Institute of Genetics and Plant Experimental Biology, Academy of Sciences of Uzbekistan, Yuqori Yuz, \\ Qibray Region, Tashkent 111226, Uzbekistan
}

Correspondence should be addressed to Ibrokhim Y. Abdurakhmonov, genomics@uzsci.net

Received 28 July 2010; Revised 11 October 2010; Accepted 24 January 2011

Academic Editor: Rhona H. Borts

Copyright ( $) 2011$ Marina F. Sanamyan et al. This is an open access article distributed under the Creative Commons Attribution License, which permits unrestricted use, distribution, and reproduction in any medium, provided the original work is properly cited.

\begin{abstract}
The use of aneuploid lines significantly increases the effectiveness of molecular-genetic analysis and the development of superior quality breeding lines via substitutions by alien chromosomes. To date, however, a complete set of aneuploid series for each cotton chromosome is not available. Here, we present the development of a monosomic stock collection of cotton (Gossypium hirsutum L.) from Uzbekistan, including the origin of 92 primary monosomics, meiotic metaphase-I analysis, study of tetrads of microspores, pollen fertility, and monosomic transmission rates for some monosomic lines. We report desynaptic effects of some monosomes detected both in parental and daughter monosomics, a positive role of interchanges in translocation heterozygous monosomics due to selective advantages of gametes with deficiency and a simultaneous interchange, pollen fertility variation, and strong differences in transmission rates. This monosomic cotton collection, developed using single genome background, will be useful for future breeding, genetic, cytogenetic, and molecular-genetic investigations of the cotton genome.
\end{abstract}

\section{Introduction}

The cultivated Gossypium spp. (cotton) is an important, natural fiber crop as well as an important source of food, feed, fuel, and other products of significant economic value. The worldwide economic impact of the cotton industry is estimated to be $\sim \$ 500$ billion/yr with an annual utilization of $\sim 115$ million bales or $\sim 27$ million metric tons of cotton fiber $[1-3]$. Being one of the major cotton producing and exporting countries worldwide, Uzbekistan produces annually 3.5 to 4 million tons of raw cotton fiber and exports cotton fiber valued at $\sim \$ 0.9$ to 1.2 billion. Therefore, development of genetic resources for cotton has been a priority of cotton science in Uzbekistan. Consequently, over the past century, one of the largest cotton germplasm collections, including isogenic, inbred lines, recombinant inbred lines (RIL), elite AD allotetraploid varieties (Gossypium hirsutum L. and Gossypium barbadense L.), monosomic, and translocation lines along with wild, primitive, and extant representatives of the A- to K-genome groups, has been collected from all over the world, curated, and developed in the Cotton Research Institutes of Uzbekistan [4].

Cultivated allotetraploid cotton, G. hirsutum $(2 n=52)$, is tolerant to the loss of individual chromosomes or their arms. For many years, efforts toward cotton monosome discovery among the varietal, hybrid, and irradiated populations of cotton as well as among cytogenetic lines were carried out in the USA [5-9]. Up to 1985, monosomes for 15 of 26 nonhomologous chromosomes had been isolated and identified [10]. Since then, in spite of great efforts, there has been minimal success in isolating the rest of 11 monosomes using radiation techniques. A new monosome for chromosome 23 was revealed and identified by meiotic fluorescence in situ hybridization (FISH) in the progeny of interspecific cross in the USA [11], and recently another new monosome for chromosome 21 in cotton was reported [12]. 
In Uzbekistan, independent investigations on creation of cytogenetic lines in G. hirsutum using numerous chromosome aberrant radiomutant plants have been carried out [13-15]. As a result, unlike other multiple-genotype-derived cytogenetic collections for cotton, a new set of monosomic and translocation lines have been developed from the common genetic background of the highly inbred line L-458 (G. hirsutum). Some of these monosomes have been characterized with new cytogenetic and biomorphologic characteristics. Previously, we reported our initial study on the origin of 67 primary monosomics obtained from $\mathrm{M}_{1}$ and $\mathrm{M}_{2}$ generations after irradiation [13]. Later, we reported on the cytology of 3 desynaptic parental cotton plants and their 11 monosomic progenies as well as chromosome transmission rates in 26 monosomics families [14]. However, a detailed characterization of our entire monosomic collection has not been done. Here, we report cytogenetic features for 92 primary monosomics including new monosomics detected in $\mathrm{M}_{3}$ generation, newly developed monosomic lines from these 92 primary monosomics, 4 novel desynaptic parental cotton plants and their 4 monosomic progenies, and 19 new monosomic families. We also report new information for 16 of 26 previously reported [14] monosomic families.

\section{Materials and Methods}

2.1. Plant Materials. Monosomic lines were developed in a common genetic background of the highly inbred line L-458 G. hirsutum L. obtained through multiple generations of selfpollination $\left(\mathrm{F}_{20}\right)$ of $108-\mathrm{F}$ variety. Since all of monosomics were isolated from a common genetic background, some differences observed among them can be attributed to differences in their monosomes. Most of the monosomics were isolated after irradiation of seeds by thermal neutrons or pollen $\gamma$-irradiation directly in $\mathrm{M}_{1}, \mathrm{M}_{2}$, and $\mathrm{M}_{3}$ generations and higher generations of $\mathrm{M}_{4}$ to $\mathrm{M}_{6}$ were obtained by selfpollination in subsequent years for further genetic analysis. Other monosomic plants were detected in the desynaptic or translocation heterozygote progenies.

2.2. Irradiation Techniques. Two types of irradiation, thermal neutron irradiation of seeds and pollen $\gamma$-irradiation of L-458 line, were used. Irradiation of seeds with thermal neutrons was carried out at the biological channel reactor VVR-SM (Institute of Nuclear Physics of Academy of Science of Republic of Uzbekistan, Tashkent, Uzbekistan). Doses of $15,25,27$, and $35 \mathrm{~Gy}$ were used. For pollen irradiation, mature pollen of L-458 were given $\gamma$-ray treatment of 10,15 , 20 , and $25 \mathrm{~Gy}\left(\mathrm{Co}^{60}\right.$, Central Asian Institute of Silk, Tashkent, Uzbekistan) and thereafter were used for pollinating the flowers that were emasculated and enclosed in parchment bags to prevent cross pollination.

2.3. Growing Conditions. All $\mathrm{M}_{1}$ plants as well as some $\mathrm{M}_{2}$ plant families with multiple seeds were grown under field conditions. All the progeny of abnormal plants with a few seeds from $M_{2}$ and $M_{3}$ generations, seeds of desynaptic plants, monosomic translocation heterozygotes, and selfed or outcrossed monosomic plants were germinated on moist filter paper in petridishes at $28^{\circ} \mathrm{C}$. Plants were then transplanted into plastic pots with soil. All seedlings were transplanted to greenhouse land soil, and when the first true leaves emerged, transplants were immediately irrigated.

2.4. Cytological Analyses. For studies of chromosome pairing at metaphase-I (MI) of meiosis, flower buds were fixed in the morning, after the removal of calyx and corolla, in a solution of $96 \%$ alcohol and acetic acid $(7: 3)$. Buds were kept at room temperature for 3 days then immersed in fresh fixative and stored at $4^{\circ} \mathrm{C}$. For cytological preparations, buds were rinsed in tap water before being examined for meiotic associations in the pollen mother cells (PMCs) using the iron acetocarmine squash technique [13-17]. Analyses of chromosomal changes were carried out on the basis of MI associations at the first meiosis of originally isolated monosomic plants $\left(\mathrm{M}_{1}-\mathrm{M}_{3}\right)$. In monosomic plants and their hybrids, the sizes of univalents were regularly estimated in each subsequent higher generation to check for univalent shifts. The development of PMCs was examined at the tetrad stage for each plant. The meiotic index was calculated as the percentage of normal tetrads in a total sporad [18], and pollen fertility was estimated by acetocarmine staining.

2.5. Transmission of the Monosomes. Transmission of the monosomes in $\mathrm{M}_{4}-\mathrm{M}_{6}$ progenies was studied in selfed or outcrossed populations of the monosomic plants. We studied transmission of monosomes in 33 selfed and 12 outcrossed progenies that are detailed in Table 4. All cytological observations were made using Biomed (Leica, Heerburg, Switzerland) or Laboval (Carl Zeiss, Germany) microscopes. Monosomics were numbered in detection order (Mo1-Mo92), and lines were maintained vegetatively in the greenhouse of National University of Uzbekistan.

\section{Results and Discussion}

3.1. Origin of the Cotton Primary Monosomics. Between 1987 and 2007, we developed a total of 92 G. hirsutum primary monosomics from the common genetic background of the highly inbred line L-458 (G. hirsutum) after irradiation of seeds by thermal neutrons or pollen $\gamma$-irradiation directly in $M_{1}, M_{2}$, and $M_{3}$ generations (for some examples, see Figure 1). Most of them (74 of 92) arose from the two irradiation types directly in $\mathrm{M}_{1}, \mathrm{M}_{2}$, and $\mathrm{M}_{3}$ generations (Table 1). The remaining 18 monosomic plants resulted from chromosome aberrant progenies (desynapsis and interchanges, Table 2). Most of the primary monosomics (34) were induced in the $M_{1}$ generation as a result of pollen $\gamma$ irradiation by doses of 10, 15, 20, and 25 Gy (Table 1). Seven of the monosomic plants had simultaneously independent chromosome interchanges. More than $70 \%$ of $\mathrm{M}_{1}$ primary monosomics (25 of 34) were induced by high doses of pollen irradiation (20-25Gy) (Table 1). The number of monosomics detected declined in subsequent generations (24 and 6, resp.), and one $\mathrm{M}_{3}$ monosomic (Mo54) also displayed heterozygous translocation. 


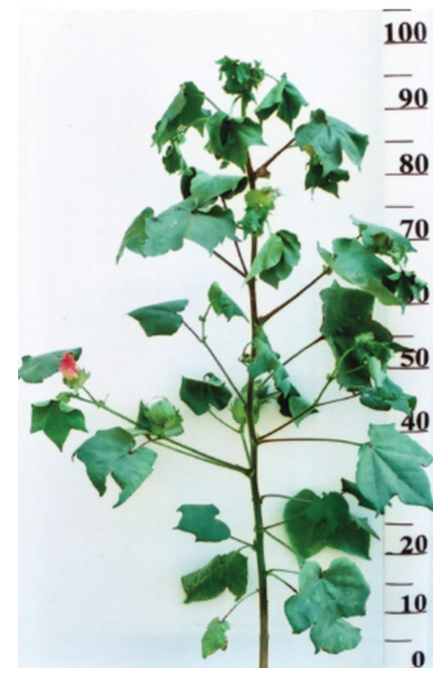

(a)

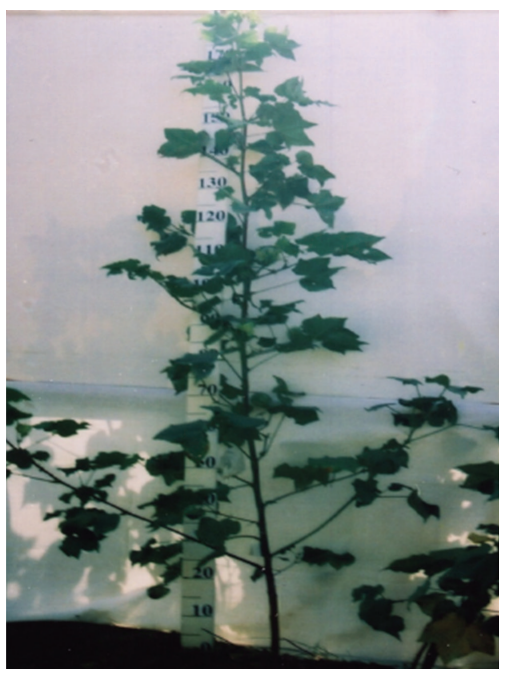

(c)

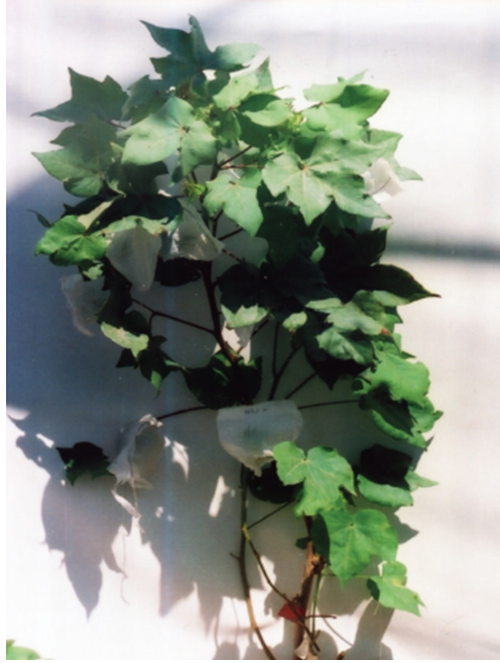

(b)

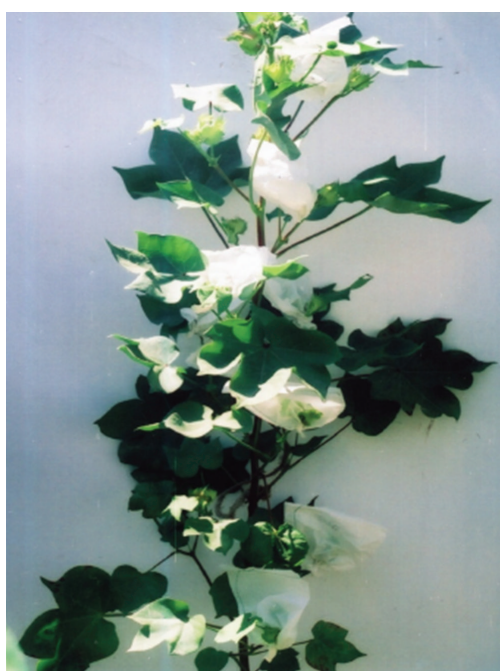

(d)

Figure 1: Examples of monosomic plants along with original parental line: (a) control plant L-458; (b) Mo71; (c) Mo80; (d) Mo16. Meiotic configuration of these plants was shown in Figure 2.

Similar analyses of cotton plants from seed irradiation with thermal neutrons at doses of 15, 25, 27, and $35 \mathrm{~Gy}$ revealed fewer primary monosomics. There were only 10 plants from three generations studied after irradiation; moreover, four of them were also interchanged heterozygotes. In the $\mathrm{M}_{1}$ generation, there were only 4 chromosomedeficient plants, 3 of them from the 15 Gy dose and one from the 35 Gy dose. Similarly, 4 monosomic plants were isolated in $\mathrm{M}_{2}$ generation in all 4 doses and two monosomic plants were identified from $\mathrm{M}_{3}$.

Previous results demonstrated that pollen $\gamma$-irradiation with doses of 20 and $25 \mathrm{~Gy}$ was the most effective to isolate many chromosome deficient plants [16, 17]. Combined results showed that in $\mathrm{M}_{1}, \mathrm{M}_{2}$, and $\mathrm{M}_{3}$ generations, there were $39(60.9 \%)$ monosomic plants. These results do not correspond with the data of Galen and Endrizzi [7] who observed more monosomic plants in lower doses (4 Gy) in comparison with higher doses (12 Gy).

In addition to traditional radiation-induced cotton monosomics, we used the desynaptic effects which have been found to be a useful source of aneuploidy in other crops. Although desynaptic plants in different crops are usually sterile or show extremely low fertility, the desynaptic cotton plant $1063 / 6_{3}-13$ had semisterile pollen due to different numbers of unpaired univalents (from 2 to 28 ) in PMCs. This desynapsis level may be regarded as intermediate. Another five desynaptic plants were characterized with weak desynapsis level and formed from 2 to 12 univalents. As a result, 16 primary monosomics were isolated from the progenies of 6 desynaptic plants and one unexamined plant from the desynaptic plant progeny (Table 2). 
TABLE 1: The origin of the cotton primary monosomics from cytogenetic collection developed in Uzbekistan (radiation).

\begin{tabular}{|c|c|c|c|c|}
\hline \multirow{2}{*}{$\begin{array}{l}\text { Dose of } \\
\text { irradiation (Gy) }\end{array}$} & \multicolumn{3}{|c|}{ Number of primary monosomics* } & \multirow{2}{*}{ Monosomic lines** } \\
\hline & $\mathrm{M}_{1}$ & $\mathrm{M}_{2}$ & $\mathrm{M}_{3}$ & \\
\hline \multicolumn{5}{|c|}{ Irradiation of seeds by thermal neutrons } \\
\hline 15 & 3 & 1 & 0 & - \\
\hline 25 & 0 & 1 & 0 & - \\
\hline 27 & 0 & 1 & 2 & Mo1 \\
\hline 35 & 1 & 2 & 0 & Mo56, Mo62 \\
\hline Total & 4 & 4 & 2 & 3 \\
\hline \multicolumn{5}{|c|}{ Irradiation of pollen by gamma rays } \\
\hline 10 & 5 & 4 & 2 & Mo10, Mo39, Mo40, Mo50, Mo81, Mo82 \\
\hline 15 & 4 & 9 & 1 & Mo3, Mo31, Mo53 \\
\hline 20 & 11 & 8 & 3 & $\begin{array}{l}\text { Mo4, Mo7, Mo11, Mo22, Mo27, Mo28, Mo34, Mo35, } \\
\text { Mo36, Mo66, Mo75, Mo89 }\end{array}$ \\
\hline 25 & 14 & 3 & 0 & $\begin{array}{l}\text { Mo9, Mo13, Mo15, Mo16, Mo17, Mo19, Mo38, Mo46, } \\
\text { Mo48, Mo76, Mo77 }\end{array}$ \\
\hline Total & 34 & 24 & 6 & 32 \\
\hline
\end{tabular}

${ }^{*}$ A total number of primary monosomics in Table 1 is 74 that were developed using thermal neutron (10 monosomics) and gamma ray (64 monosomics) treatments. Remaining 18 primary monosomics were developed from desynaptic plants that were shown in Table $2 .{ }^{* *}$ From these 74 primary monosomics developed using irradiation, 34 monosomic lines were developed, and this number does not reflect the fertility or transmission ability of primary monosomics.

All the initial desynaptic plants differed by their number of unpaired chromosomes (from 2 to 28 univalents). Disruptions in unpaired chromosome disjunction led to a random univalent distribution between the cell division poles, forming numerous tetrads with micronuclei (to $13.42 \pm 0.87 \%$ ), lowering of meiotic index (to $75.07 \pm 1.11 \%$ in 356/8 desynaptic plant), and pollen fertility reduction to semisterility $(61.35 \pm 2.43 \%)$. Meiotic index is a normal tetrad percentage and an indicator of meiotic stability proposed by Love [18] for evaluation of meiosis in wheat. We observed that pollen fertility varied among the flowers on the same plant (from $2.61 \pm 1.27 \%$ to $91.81 \pm 1.18 \%$ in 179/2 desynaptic plant; Table 2).

It should be noted that the use of an asynaptic genotype in tobacco [19] and desynaptic effect in wheat Triticum aestivum L. nulli-3B allowed complete monosomic series to be developed $[20,21]$ in comparison with cotton [22]. Similar genotype detection in cotton should facilitate the discovery of de novo monosomes. Study of desynaptic progenies revealed one unique desynaptic plant (356/8). This plant produced monosomics in high frequency with a small size of univalents and strong phenotypic differences, suggesting monosomy for different chromosomes of cotton genome. Previously, we identified two new monosomics (Mo30 and Mo67) using desynaptic cotton genotype [13].

\subsection{Meiotic Metaphase-I in Cotton Primary Monosomics.} Meiotic metaphase-I analysis of 92 cotton primary monosomics revealed modal chromosome pairing with 25 bivalents and one univalent in 38 plants. Forty-nine monosomic plants were characterized with the presence of additional univalents. Thus, in 32 monosomics, the formation of three univalents in some PMCs was observed due to lack of pairing of single pair of chromosomes. Three monosomics formed five univalents in some PMCs suggesting the absence of pairing in two chromosome pairs. Another five monosomics were characterized with the presence of unpaired chromosomes in 20-30\% PMCs. In 8 chromosome-deficient plants, a strong desynaptic effect was detected as they formed from 3 to 11 univalents in 40-60\% PMCs studied. In the monosomic plant Mo52, detected in $\mathrm{M}_{2}$ generation after pollen $\gamma$-irradiation, none of the studied PMCs revealed normal chromosome pairing because we noted 3 to 15 univalents.

Results reported on wheat [21], tobacco [19], and Egyptian Henbane [23] indicate that there is a partial desynaptic effect in some of their monosomes. Monosomic analysis established the presence of the main genes slowing homologous pairing in wheat chromosomes $2 \mathrm{~B}$ and $3 \mathrm{~B}$ of the Avrora variety [24]. Chromosome pairing reduction in cotton monosomics with desynapsis could be caused by specific influence of some genes as reported previously [25]. Because the above-mentioned monosomics were detected after irradiation, they might have desynaptic gene mutations, occurring independently of monosomy. In the USA Cotton Cytogenetic Collection, monosomes were also isolated from the partially desynaptic plant progenies [5, 26, 27]; however, these phenomena were not fully characterized. In spite of a lack of reporting on chromosome pairing in monosomics from the USA Cytogenetic Collection [28], it is known that 6 monosomes were isolated from the progenies of other aneuploids as a result of univalent shifts [27]. These were due to disturbances of chromosome behavior in parental monosomics.

In seven of our monosomes (Mo6, Mo7, Mo19, Mo30, Mo56, Mo61, and Mo62), besides univalents and bivalents, rare trivalents (from $0.04 \pm 0.04$ to $0.12 \pm 0.06$ in average per cell) formed at metaphase-I of meiosis. This suggested association of univalents with two homeologous chromosomes. Moreover, two of them (Mo56 and Mo61) were also 
TABLE 2: Chromosome pairing at meiotic metaphase-I observed in PMCs and pollen fertility in the cotton desynaptic parental plants (DPPs) and their monosomics (Mo) progenies.

\begin{tabular}{|c|c|c|c|c|c|c|c|c|}
\hline \multirow{3}{*}{ Material } & \multirow{3}{*}{ Mo } & \multirow{3}{*}{$\begin{array}{l}\text { Chromosome } \\
\text { number }\end{array}$} & \multicolumn{4}{|c|}{ Chromosome associations } & \multicolumn{2}{|c|}{ Pollen fertility } \\
\hline & & & \multirow[t]{2}{*}{$\begin{array}{l}\text { Total number } \\
\text { of cells }\end{array}$} & \multirow{2}{*}{$\begin{array}{l}\text { Number of } \\
\text { univalents }\end{array}$} & \multicolumn{2}{|c|}{$\begin{array}{c}\text { Frequency of chromosome } \\
\text { associations (in average per cell) }\end{array}$} & \multirow{2}{*}{$\begin{array}{l}\text { Total number } \\
\text { of pollen } \\
\text { grains }\end{array}$} & \multirow[t]{2}{*}{ Fertility, (\%) } \\
\hline & & & & & univalents & bivalents & & \\
\hline $1609 / 6_{6}-\mathrm{DPP}$ & & 52 & 60 & $2-12$ & $4.77 \pm 0.48$ & $23.62 \pm 0.24$ & 656 & $70.12 \pm 1.79$ \\
\hline $1609 / 6_{6}-22$ & Mo55 & 51 & 22 & $1-3$ & $1.45 \pm 0.18$ & $24.77 \pm 0.09$ & 466 & $93.99 \pm 1.10$ \\
\hline $1609 / 6_{6}-4$ & Mo69 & 51 & 33 & 1 & $1.00 \pm 0.00$ & $25.00 \pm 0.00$ & 499 & $98.27 \pm 0.58$ \\
\hline $1063 / 6_{3}-13-D P P$ & & 52 & 42 & $2-28$ & $14.33 \pm 0.9$ & $18.83 \pm 0.45$ & 405 & $65.68 \pm 2.36$ \\
\hline $1063 / 6_{3}-13_{3}$ & Mo70 & 51 & 25 & $1-3$ & $1.08 \pm 0.08$ & $24.96 \pm 0.04$ & 639 & $95.15 \pm 0.85$ \\
\hline $1063 / 6_{3}-13_{4}$ & Mo71 & 51 & 24 & 1 & $1.00 \pm 0.00$ & $25.00 \pm 0.00$ & 352 & $96.02 \pm 1.04$ \\
\hline $1063 / 6_{3}-13_{5}$ & Mo72 & 51 & 21 & 1 & $1.00 \pm 0.00$ & $25.00 \pm 0.00$ & 632 & $96.87 \pm 0.69$ \\
\hline $1063 / 6_{3}-13_{6}$ & Mo73 & 51 & 30 & $1-3$ & $1.47 \pm 0.15$ & $24.77 \pm 0.08$ & 612 & $98.53 \pm 0.49$ \\
\hline $1570 / 14_{9}-3-D P P$ & & 52 & 42 & $2-8$ & $2.43 \pm 0.31$ & $24.79 \pm 0.15$ & 440 & $94.09 \pm 1.12$ \\
\hline $1570 / 14_{9}-3_{18}$ & Mo78 & 51 & 18 & 1 & $1.00 \pm 0.00$ & $25.00 \pm 0.00$ & - & - \\
\hline $\begin{array}{l}\text { 1570/14 } 9-13- \\
\text { DPP }\end{array}$ & & 52 & 15 & $2-6$ & $2.67 \pm 0.46$ & $24.67 \pm 0.23$ & 467 & $95.29 \pm 0.98$ \\
\hline $1570 / 14_{9}-13_{7}$ & Mo85 & 51 & 16 & 1 & $1.00 \pm 0.00$ & $25.00 \pm 0.00$ & 984 & $97.97 \pm 0.45$ \\
\hline 179/2-DPP & & 52 & 32 & $2-8$ & $2.50 \pm 0.37$ & $24.75 \pm 0.19$ & $157-537$ & $\begin{array}{l}2.61 \pm 1.27- \\
91.81 \pm 1.18\end{array}$ \\
\hline $179 / 2_{12}$ & Mo87 & 51 & 20 & 1 & $1.00 \pm 0.00$ & $25.00 \pm 0.00$ & $217-693$ & $\begin{array}{l}40.09 \pm 3.33- \\
92.93 \pm 0.97\end{array}$ \\
\hline 356/8-DPP & & 52 & 18 & 2 & $1.67 \pm 0.18$ & $25.17 \pm 0.09$ & 401 & $61.35 \pm 2.43$ \\
\hline $356 / 8_{5}$ & Mo58 & 51 & 33 & $1-3$ & $1.12 \pm 0.08$ & $24.94 \pm 0.04$ & 685 & $81.02 \pm 1.50$ \\
\hline $356 / 8_{6}$ & Mo59 & 51 & 24 & 1 & $1.00 \pm 0.00$ & $25.00 \pm 0.00$ & $222-1292$ & $\begin{array}{l}2.25 \pm 1.00- \\
70.12 \pm 1.27\end{array}$ \\
\hline $356 / 8_{7}$ & Mo60 & 51 & 22 & 1 & $1.00 \pm 0.00$ & $25.00 \pm 0.00$ & 307 & $38.44 \pm 2.78$ \\
\hline $\begin{array}{l}356 / 8_{8} \text {-unknown } \\
\text { caryotype }\end{array}$ & & - & - & - & 一 & - & 452 & $53.98 \pm 2.34$ \\
\hline $356 / 8_{8}-14$ & Mo79 & 51 & 22 & 1 & $1.00 \pm 0.00$ & $25.00 \pm 0.00$ & 666 & $92.94 \pm 0.99$ \\
\hline $356 / 8_{8}-15$ & Mo80 & 51 & 20 & 1 & $1.00 \pm 0.00$ & $25.00 \pm 0.00$ & 447 & $99.78 \pm 0.22$ \\
\hline $356 / 8_{8}-5$ & Mo84 & 51 & 39 & $1-3$ & $1.41 \pm 0.13$ & $24.79 \pm 0.07$ & 322 & $98.14 \pm 0.75$ \\
\hline $356 / 8_{8}-2$ & Mo91 & 51 & 19 & $1-3$ & $1.11 \pm 0.11$ & $24.95 \pm 0.05$ & $65-726$ & $\begin{array}{c}53.85 \pm 6.18 \\
89.81 \pm 1.12\end{array}$ \\
\hline
\end{tabular}

DPP: desynaptic parental plants showed in bold-faced letters.

characterized with additional univalents. The other 12 cotton primary monosomics showed quadrivalent associations with different frequencies suggesting heterozygosity for their translocations. Although we cannot address this with our present data, meiotic associations of univalents with other chromosomes could occasionally be due to homology, or small translocations or duplications, and should be carefully interpreted.

Preliminary evaluation of subgenome assignment showed that translocations in two monosomic plants (Mo9; Mo22) might have been of the $A_{t}$-genome because of their large quadrivalents. Three other monosomics had small quadrivalents (Mo1, Mo54, and Mo63) that apparently originated from the $\mathrm{D}_{t}$-genome. The remaining chromosome-deficient plants had quadrivalents of medium size, and their subgenome localization should be determined by genome analysis using the D-genome diploid plants. Ten monosomics with simultaneous translocation heterozygosity were characterized with low quadrivalent frequency, and only two of them (Mo23 and Mo24) had high quadrivalent frequencies (to $0.60 \pm 0.13$ in average per cell). Besides, 5 monosomics (Mo8, Mo9, Mo23, Mo24, and Mo61) had also additional univalents.

Analyses of the sizes of monosomes revealed medium univalent size in 43 monosomics (Figure 2(a)), whereas there were 21 monosomics with large univalents (Figure 2(b)). The number of monosomics having small univalents was slightly higher (27); moreover, among these, 6 monosomics with very small univalents were detected (Figure $2(\mathrm{c})$ ). Therefore, according to a preliminary assignment of monosomes on the basis of their sizes to the subgenomes, 21 large monosomes can be assigned to the $A_{t}$-genome and 27 monosomes of small sizes to the $\mathrm{D}_{t}$-genome. Since it is known that only 3 chromosome pairs of $G$. hirsutum have long arms that 


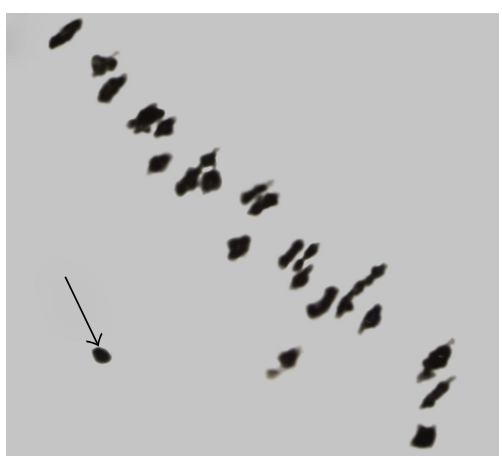

(a)

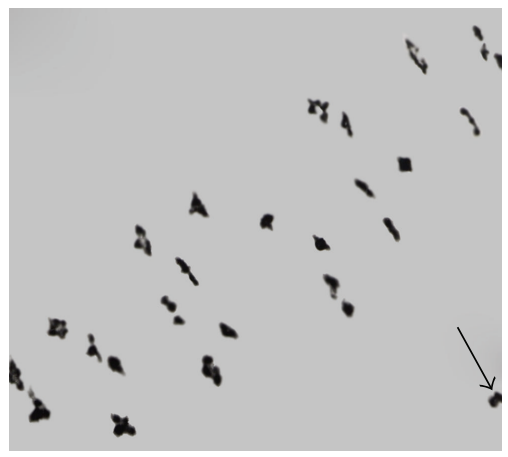

(b)

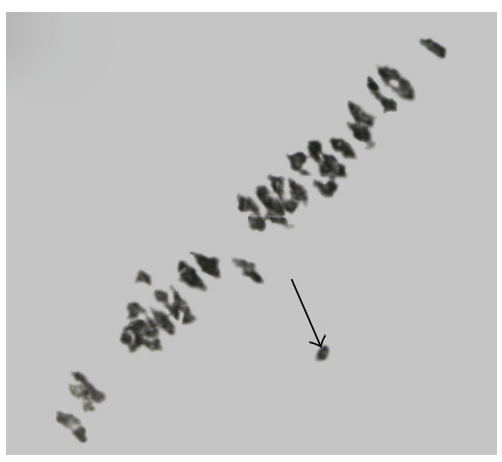

(c)

FIgure 2: Meiotic configurations in primary monosomics in cotton G. hirsutum. Meiotic metaphase-I cells showing 25 bivalents and 1 univalent in (a) Mo71 (medium univalent size); (b) Mo16 (large univalent size); (c) Mo80 (small univalent size). The arrows point to the univalents. Note that the background of figures was cleaned using Adobe Photoshop CS 2 version 9.0.

are two or three times the length of the short arms [29], monosomes of medium sizes demand special analyses using translocations with subgenome assigned interchanges. It should be mentioned that studies of subgenome assignment of unidentified monosomes of medium sizes showed the $\mathrm{A}_{t^{-}}$ subgenome location [28] and significant deviation from the expected $1: 1$ ratio of the $A_{t}$-subgenome monosome number to the $\mathrm{D}_{t}$-subgenome ones. Independent analyses of the same monosomic stocks revealed that $\mathrm{A}_{t}$ - versus $\mathrm{D}_{t}$-genome monosome number ratio varied from $5: 1[27,30]$ to $1.7: 1$ [28]. The latter ratio was much smaller than those previously reported. These findings also implied that preferential loss of the $\mathrm{A}_{t}$-genome chromosomes was caused by specific genetic regulation system of chromosome disjunction and was not due to size of monosomes [28]. In our experiments, we detected a nearly $2: 1$ ratio of the $A_{t}$ - to the $D_{t}$-genome monosomes if we regard monosomes of medium sizes to be from $A_{t}$-genome. Our ratio is not significantly different from the ratio given by Myles and Endrizzi [28]. This confirms a greater tolerance of $G$. hirsutum to loss of the large $\mathrm{A}_{t}$-genome chromosome than the small $\mathrm{D}_{t}$-genome chromosomes.

\subsection{Analyses of Tetrads of Microspores and Pollen Fertility} in Cotton Monosomics. Analysis of tetrads was carried out for 87 primary monosomics of our collection. Most of the monosomics (73 or $83.91 \%$ ) had a higher meiotic index (more than 90\%) than that of the control plants $(95.11 \pm 0.46 \%)$. This indicates regular univalent chromosome disjunction. Fourteen of the monosomics (16.09\%) were characterized with lowering of meiotic index from $89.32 \%$ (Mo74) to $68.32 \%$ (Mo4). Moreover, 10 of the monosomics had a smaller reduction of meiotic index (to 80\%) than did two others (Mo4 and Mo16). These monosomics were induced in $\mathrm{M}_{1}$ generation after pollen $\gamma$ irradiation in doses of 20 and $25 \mathrm{~Gy}$, leading to strong meiotic index reduction (to $68.32 \pm 1.10 \%$ and $76.07 \pm 0.93 \%$, resp.). We also observe an increase of percentage of tetrads with micronuclei (to $6.87 \pm 0.60 \%$ and $21.56 \pm 0.90 \%$, resp.) in comparison with the control line $(1.42 \pm 0.25 \%$; Table 3$)$. Two other monosomics (Mo88 and Mo90), selected from $\mathrm{M}_{3}$ generation after irradiation of seeds by thermal neutrons and pollen with $\gamma$-rays, respectively, were characterized with different meiotic index in various buds. Variation limits were also observed for the number of tetrads with micronuclei (Table 3).

Meiotic index decrease in 6 monosomics (Mo16, Mo28, Mo52, Mo74, Mo88, and Mo90) could be explained with the presence of additional univalents at meiotic metaphase-I. In contrast, meiotic index decrease in 4 monosomics (Mo8, Mo21, Mo23, and Mo57) was connected with simultaneous translocation heterozygosity that led to chromosome disjunction disturbances and the production of tetrads with micronuclei. However, meiotic index decrease in 3 monosomics with the modal chromosome pairing (Mo4, Mo34, and Mo37) and increase of number of tetrads with micronuclei in Mo4 (to $6.87 \pm 0.60 \%$ ) directly demonstrated disturbances in monosome disjunction and imbalanced gamete formation. However, unlike cotton, in wheat monosomics, many micronuclei were observed in tetrads that suggested high univalent misdivision rate $[31,32]$.

Monosomic plants with a reduced meiotic index also differed from each other by pollen fertility. Complete pollen sterility was recorded in two monosomics (Mo57 and Mo74); however, partial female fertility provided seed set from outcrossing. Such strong variability of pollen fertility in the monosomics with reduced meiotic index was explained with both cytogenetic status influence and specific radiation action especially in 8 monosomics isolated from $\mathrm{M}_{1}$ generation after irradiation. 
TABLE 3: Analyses of tetrads and pollen fertility in cotton primary monosomics (Mo) with reduced meiotic index.

\begin{tabular}{|c|c|c|c|c|c|c|}
\hline \multirow{2}{*}{ Mo } & \multirow{2}{*}{$\begin{array}{l}\text { Dose of } \\
\text { irradiation, } \\
(\mathrm{Gy})\end{array}$} & \multicolumn{3}{|c|}{ Microsporocytes } & \multicolumn{2}{|c|}{ Pollen fertility } \\
\hline & & $\begin{array}{l}\text { Total number of } \\
\text { microsporocytes }\end{array}$ & $\begin{array}{l}\text { Meiotic } \\
\text { index* }\end{array}$ & $\begin{array}{l}\text { Tetrads with } \\
\text { micronuclei, \% }\end{array}$ & $\begin{array}{c}\text { Total number } \\
\text { of pollen } \\
\text { grains }\end{array}$ & Fertility, \% \\
\hline Mo4 & 20 & 1777 & $68.32 \pm 1.10$ & $6.87 \pm 0.60$ & 475 & $93.47 \pm 1.13$ \\
\hline Mo6 & 20 & 1654 & $87.85 \pm 0.80$ & $2.48 \pm 0.38$ & 207 & $74.40 \pm 3.03$ \\
\hline Mo8 & 15 & 695 & $80.29 \pm 1.51$ & $2.01 \pm 0.53$ & 593 & $61.72 \pm 2.00$ \\
\hline Mo16 & 25 & 2110 & $76.07 \pm 0.93$ & $21.56 \pm 0.90$ & 185 & $5.43 \pm 1.67$ \\
\hline Mo21 & 15 & 2129 & $89.24 \pm 0.67$ & $5.87 \pm 0.51$ & 387 & $18.58 \pm 1.98$ \\
\hline Mo23 & 20 & 765 & $88.76 \pm 1.14$ & $8.37 \pm 1.00$ & 132 & $81.82 \pm 3.36$ \\
\hline Mo28 & 20 & 858 & $87.18 \pm 1.14$ & $2.10 \pm 0.49$ & 450 & $70.67 \pm 2.15$ \\
\hline Mo34 & 20 & 1981 & $88.54 \pm 0.72$ & $2.68 \pm 0.36$ & 358 & $46.23 \pm 2.64$ \\
\hline Mo37 & 20 & 1317 & $81.85 \pm 1.06$ & $0.91 \pm 0.26$ & 185 & $82.16 \pm 2.81$ \\
\hline Mo52 & 15 & 1326 & $89.00 \pm 0.86$ & $2.56 \pm 0.43$ & 135 & $72.60 \pm 3.84$ \\
\hline Mo57 & 15 & 2684 & $87.15 \pm 0.65$ & $3.95 \pm 0.38$ & 325 & 0 \\
\hline Mo74 & 15 & 2295 & $89.32 \pm 0.64$ & $4.44 \pm 0.43$ & 340 & 0 \\
\hline Mo88 & 27 & $972-1785$ & $\begin{array}{l}47.94 \pm 1.60 / \\
95.52 \pm 0.49\end{array}$ & $\begin{array}{c}0.62 \pm 0.25 / \\
0.22 \pm 0.11\end{array}$ & 983 & $91.96 \pm 0.87$ \\
\hline Mo90 & 20 & $203-2068$ & $\begin{array}{c}12.32 \pm 2.31- \\
98.69 \pm 0.25\end{array}$ & $6.90 \pm 1.78-0$ & 2326 & $93.98 \pm 0.49$ \\
\hline $\mathrm{L}-458$ & 0 & 2190 & $95.11 \pm 0.46$ & $1.42 \pm 0.25$ & 3200 & $96.44 \pm 0.33$ \\
\hline
\end{tabular}

$\mathrm{L}-458$ is original parental (control) genotype; meiotic index is a percentage of normal tetrads in all sporad.

Pollen fertility after acetocarmine staining was studied in 90 primary cotton monosomics isolated mainly from different types of irradiation. Although the acetocarmine-based pollen fertility considered relatively insensitive method, it is widely used (i.e., see [33]) for preliminary screening of pollen quality in plants. High pollen fertility was detected only in 28 plants with chromosome deficiencies that pointed out probable early haplo-deficient microspore abortion prior to mature pollen stage. Remaining monosomics were characterized with pollen fertility decrease. Thus, 17 monosomics had small reductions in pollen fertility (to 70\%), 11semisterile pollen (to 40\%) and 15-strong pollen fertility reduction (to 5\%). Pollen sterility was established in 6 monosomics (Mo5, Mo7, Mo10, Mo44, Mo45, and Mo47) derived from $\mathrm{M}_{1}$ generation after irradiation of pollen and in two monosomics (Mo57 and Mo74) isolated after thermal neutron seed irradiation (Figure 3). Monosomics Mo5 and Mo44 did not produce any seeds that suggest their complete sterility. In 11 monosomics, pollen fertility varied among different flowers on the same plant; moreover, the variation limits strongly differed. Reproduced monosomics from the 3 other families (Mo22, Mo39, and Mo46) also had pollen fertility variation in different flowers on the same plant from semisterile or low to reduced pollen fertility.

Taken together, more than half of parental monosomics had partial or complete pollen sterility. After irradiation in $\mathrm{M}_{1}$ generation, pollen grain overabortion might be the result of radiation physiologic effect. However, transmission of the character to the next generations in daughter monosomics of higher generations $\left(\mathrm{M}_{4}-\mathrm{M}_{6}\right)$ was obviously connected with gene(s) responsible for pollen development

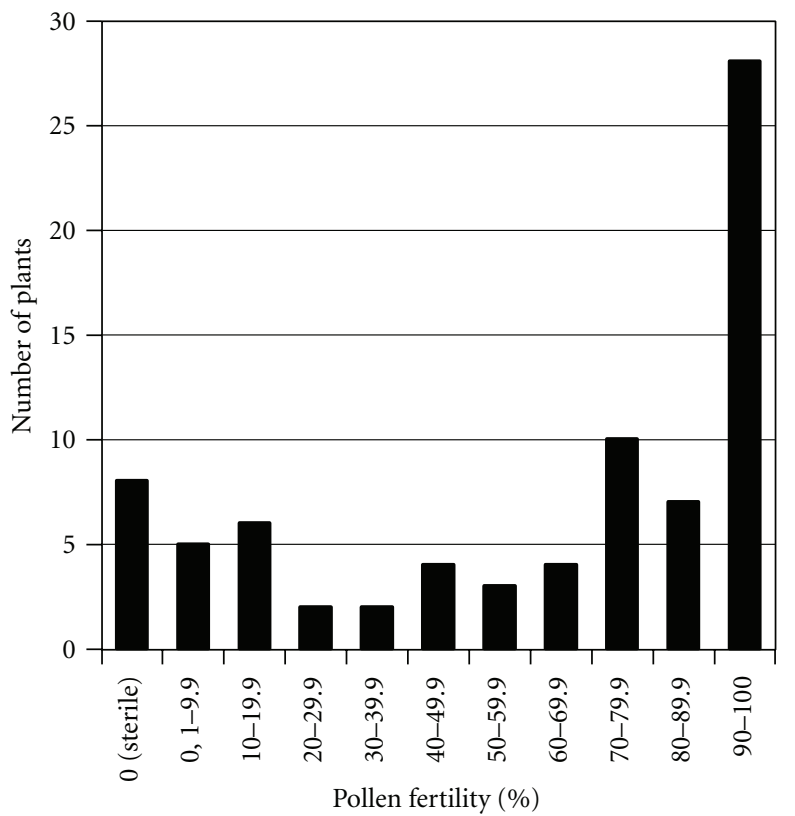

Figure 3: Percentage distribution of pollen fertility for 79 cotton monosomic plants. Note: the remaining 11 monosomics were not included in the histogram due to their varied pollen fertility level in different flowers.

located in the monosome chromosomes (Mo22, Mo39, and Mo46). In due course, the abortive pollen detection in 6 monosomic lines suggested a polygenic control of pollen development in cotton G. hirsutum [34]. In addition, 
the high pollen fertility observed in some cotton plants with chromosome deficiencies can be due to certain tolerance to aneuploidy due to the polyploid origin of G. hirsutum. At the same time, failure to transmit the majority of cotton chromosome deficiencies via pollen [10] could be due to their negative effects on male gametophyte viability in general.

We used the individual seed weight method to facilitate monosome cytotype detection. According to Douglas' opinion [35], within a single boll, monosomic seeds are lighter than normal seeds. Douglas recommended use of this marker to increase the chance of revealing rarely transmitted monosomes. However, it was unknown whether the low seed weight was a universal marker of monosomy in cotton. To study the relationship of monosomic cytotypes and individual seed weight, we weighed each of the seeds in 32 monosomic lines. Our results indicate that light seed weight is not a universal marker of monosomy in cotton. In spite of the tendency to produce light seeds in 22 monosomics, some chromosome-deficient plants were transmitted from the seeds of medium weights (3 plants) and even heavy weights ( 3 plants). Similar reproduction features were also described for wheat monosomics of Diamant 2 variety [36].

3.4. Transmission Rates of Cotton Monosomics. The reproduction of the monosomics was studied in the selfed and outcrossed progenies under field and greenhouse conditions. Comparative analysis of the cotton monosomics reproduced in the field revealed stronger morphological differences in comparison with disomic sibs as well as monosomics reproduced in the greenhouse. As a result, monosomics were reproduced in 18 progenies under field conditions. However, because of limited vegetation period, we did not manage to analyze most of the progenies and determine exact transmission frequency in the field. Eleven of them were reproduced later under greenhouse condition whereas 7 monosomics (Mo22, Mo34, Mo36, Mo39, Mo45, Mo46, and Mo53) have not been reproduced at this time. Progenies of 77 different monosomics were studied in the greenhouse. Table 4 includes data on 45 monosomics, 19 of which were reproduced for the first time. Revised data are presented for 16 of 26 monosomics characterized in our previous study [14] to show the complete information on transmission rates of the monosomics from the Uzbek Cotton Cytogenetic Collection. All monosomic families strongly differed in number of plants studied and in only 14 families were all progenies cytologically examined for monosome transmission rate. This demonstrated a large variation in transmission rate from high (44.44\% in Mo16 and Mo84) to very low $(2.38 \%$ in Mo15). The highest transmission rate (from $30.43 \%$ in Mo72 to $44.44 \%$ in Mol6 and Mo84) was observed for 8 monosomics (Mo16, Mo31, Mo66, Mo71, Mo72, Mo77, Mo82, and Mo84). This suggested haplodeficient gamete frequent transmission. On the other hand, 10 other monosomics (Mo3, Mo4, Mo9, Mo15, Mo35, Mo40, Mo56, Mo61, Mo67, and Mo85) had the lowest transmission rate (from 2.38\% in Mo15 to $9.38 \%$ in Mo67) due to rare $n-1$ gamete transmission that demanded a large population study for their recovery. The remaining 29 monosomics were transmitted with medium frequencies (from $14.29 \%$ in Mo10 and Mo74 to 29.17\% in Mo62). Significant variability in transmission rates could be explained by differences in the viability of haplo-deficient gametes involving specific chromosomes. Theoretically, after selfing, monosomics must produce progenies with $2 n, 2 n-1$, and $2 n-2$ chromosome number in the ratio $1: 2: 1$, but, in fact, cotton nullisomic gametes with $2 n-2$ are nonviable whereas $n$ and $n-1$ gametes form in unequal frequencies because of lower haplodeficient gamete viability and their uncompetitiveness in comparison with normal gametes. Thus, all the differences in detected transmission rates involve deficiencies in various chromosomes of the cotton genome. Nevertheless, transmission rate similarities in some monosomes in our collection could indicate identities that should be explored.

Similarly, the rate of the transmission of the haplodeficient gamete varied from low (4\%) in a monosome 9 to high $(49 \%)$ in a monosome 4 from the USA Cytogenetic Collection and 3 monosomics (for chromosomes 3, 9, and 16) usually transmitted with the lowest frequencies [10]. Male $n-1$ gamete transmission was recorded only in two monosomes (Mono 4 and Mono 6) that often occurred as spontaneous deficiencies in natural populations. It should be mentioned that the low transmission rate of the monosome 9 could be partially explained by abnormal cytological behavior due to existence of a genetic factor that controls one or more metabolic processes specific to embryo sac mitoses, which ensures the normal disjunction of chromosomes [28].

\subsection{Transmission of Chromosome Aberrations to the Mono-} somic Progeny. Deficiencies for one chromosome arm occurred in the progenies of seven monosomics. Thus, in three monosomic progenies (Mo17, Mo19, and Mo61) that differed with respect to monosome transmission rates (Table 4), monotelodisomics were produced due to univalent instability and resulted in misdivision. In the progenies of Mo21, Mo49, Mo54, and Mo68, daughter monosomics failed to produce, but monotelodisomics (from the progenies of Mo21, Mo49, and Mo68) and a monoisodisomic plant (from the progenies of Mo54) were detected. The results suggested an irregular univalent chromosome centromere misdivision in the parental monosomics that led to a single chromosome arm missing and formed either telocentric or isochromosome in the case of an arm doubling. Our results demonstrated the rather rare occurrence of teloand isochromosomes in the monosomic progenies studied, which showed univalent misdivision to be rare. It should be mentioned that analysis of monosomic progeny from the USA Cytogenetic Collection revealed high misdivision rate in three monosomic plants-Mono12, Mono22, and Mono25 [9, 10]. However, according to Brown's opinion [37], univalents in cotton are seldom observed in meiosis.

High heteromorphic bivalent frequency was observed in all of the six monotelodisomics (to $1.70 \pm 0.11$ in average per cell) suggesting telocentric chromosome pairing with the normal homologous chromosome (Figure 4). The various sizes of such bivalents preliminarily suggest that telosomes have different subgenome locations. Two 
TABLE 4: Transmission of the monosomes in the progenies of cotton monosomics (Mo) under greenhouse conditions.

\begin{tabular}{|c|c|c|c|c|c|c|c|}
\hline Mo & $\begin{array}{l}\text { Total no. of } \\
\text { plants }\end{array}$ & $\begin{array}{l}\text { No. of studied } \\
\text { plants }\end{array}$ & $\begin{array}{l}\text { Disomics } \\
(26 \mathrm{II})\end{array}$ & $\begin{array}{l}\text { Monotelodisomics } \\
(25 \mathrm{II}+1 \mathrm{t})\end{array}$ & $\begin{array}{l}\text { Monosomics } \\
(25 \mathrm{II}+1 \mathrm{I})\end{array}$ & $\begin{array}{c}\text { Transmission } \\
(\%)\end{array}$ & $\begin{array}{c}\text { No. of } \\
\text { progenies }\end{array}$ \\
\hline \multicolumn{8}{|c|}{ Transmission of monosomes studied in outcrossed progenies } \\
\hline (Mo1)* & 6 & 6 & 5 & 0 & 1 & 16.67 & 1 \\
\hline (Mo2) & 6 & 6 & 5 & 0 & 1 & 16.67 & 1 \\
\hline Mo3 & 29 & 24 & 23 & 0 & 1 & 4.17 & 3 \\
\hline Mo4 & 45 & 29 & 27 & 0 & 2 & 6.9 & 2 \\
\hline (Mo10) & 7 & 7 & 6 & 0 & 1 & 14.29 & 2 \\
\hline Mo11 & 52 & 34 & 24 & 0 & 10 & 29.41 & 4 \\
\hline Mo13 & 27 & 21 & 18 & 0 & 3 & 14.29 & 3 \\
\hline Mo15 & 44 & 42 & 41 & 0 & 1 & 2.38 & 5 \\
\hline (Mo28) & 5 & 5 & 4 & 0 & 1 & 20.00 & 1 \\
\hline Mo56 & 26 & 26 & 24 & 0 & 2 & 7.69 & 4 \\
\hline Mo63 & 19 & 13 & 11 & 0 & 2 & 15.38 & 2 \\
\hline (Mo74) & 12 & 7 & 6 & 0 & 1 & 14.29 & 1 \\
\hline \multicolumn{8}{|c|}{ Transmission of monosomes studied in selfed progenies } \\
\hline Mo7 & 29 & 19 & 14 & 0 & 5 & 26.32 & 2 \\
\hline Mo9 & 48 & 34 & 32 & 0 & 2 & 5.88 & 3 \\
\hline Mo16 & 22 & 18 & 10 & 0 & 8 & 44.44 & 3 \\
\hline Mo17 & 33 & 31 & 24 & 1 & 6 & 19.35 & 9 \\
\hline Mo19 & 38 & 31 & 24 & 1 & 6 & 19.35 & 4 \\
\hline (Mo27) & 9 & 9 & 7 & 0 & 2 & 22.22 & 2 \\
\hline Mo31 & 25 & 25 & 16 & 0 & 9 & 36.00 & 5 \\
\hline Mo35 & 24 & 23 & 21 & 0 & 2 & 8.70 & 3 \\
\hline Mo38 & 17 & 17 & 14 & 0 & 3 & 17.65 & 2 \\
\hline Mo40 & 33 & 33 & 32 & 0 & 1 & 3.03 & 2 \\
\hline Mo42 & 30 & 25 & 21 & 0 & 4 & 16.00 & 2 \\
\hline (Mo48) & 11 & 11 & 9 & 0 & 2 & 18.19 & 3 \\
\hline Mo50 & 37 & 26 & 20 & 0 & 6 & 23.07 & 3 \\
\hline Mo60 & 16 & 14 & 10 & 0 & 4 & 28.57 & 3 \\
\hline Mo61 & 41 & 18 & 16 & 1 & 1 & 5.56 & 3 \\
\hline Mo62 & 61 & 24 & 17 & 0 & 7 & 29.17 & 4 \\
\hline Mo66 & 31 & 31 & 20 & 0 & 11 & 35.48 & 3 \\
\hline Mo67 & 40 & 35 & 32 & 0 & 3 & 9.38 & 4 \\
\hline Mo69 & 18 & 18 & 13 & 0 & 5 & 27.78 & 2 \\
\hline Mo70 & 18 & 18 & 15 & 0 & 3 & 16.67 & 3 \\
\hline Mo71 & 20 & 20 & 13 & 0 & 7 & 35.00 & 2 \\
\hline Mo72 & 23 & 23 & 16 & 0 & 7 & 30.43 & 2 \\
\hline Mo73 & 28 & 24 & 18 & 0 & 6 & 25.00 & 2 \\
\hline Mo75 & 35 & 15 & 11 & 0 & 4 & 26.67 & 3 \\
\hline Mo76 & 31 & 18 & 14 & 0 & 4 & 22.22 & 4 \\
\hline (Mo77) & 22 & 10 & 6 & 0 & 4 & 40.00 & 1 \\
\hline Mo79 & 31 & 22 & 16 & 0 & 6 & 27.27 & 3 \\
\hline Mo80 & 48 & 20 & 17 & 0 & 3 & 15.00 & 3 \\
\hline Mo81 & 21 & 12 & 9 & 0 & 3 & 25.00 & 2 \\
\hline (Mo82) & 17 & 11 & 7 & 0 & 4 & 36.36 & 2 \\
\hline Mo84 & 31 & 18 & 10 & 0 & 8 & 44.44 & 2 \\
\hline Mo85 & 48 & 26 & 25 & 0 & 1 & 3.85 & 2 \\
\hline Mo89 & 47 & 21 & 17 & 0 & 4 & 19.05 & 3 \\
\hline
\end{tabular}

*Families shown in parenthesis are too small to provide a very informative assessment. 


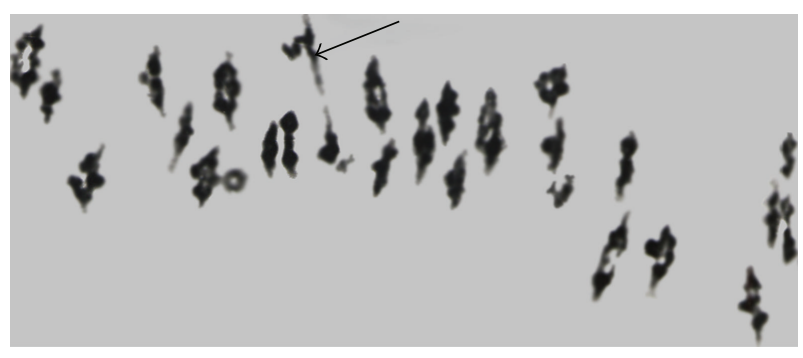

Figure 4: Meiotic metaphase-I in monotelodisomic plant from progeny Mo21, showing 25 normal bivalents and monotelodisomic bivalent (including one normal chromosome plus one telosome). The arrow indicates the monotelodisomic bivalent. Note that the background of figures was cleaned using Adobe Photoshop CS 2 version 9.0.

telosomes involved long chromosome arms whereas the remaining involved short arm of cotton chromosomes. When telosome pairing with normal homologous chromosome is absent because of lower chiasmata frequency (especially in short-arm telocentrics), two univalents of different sizes form. Moreover, with telosomes involving short chromosome arms, more cells with univalents were observed (from $23.81 \%$ to $77.78 \%$ PMC) in comparison with the telosomes for long arms (from $12.60 \%$ to $14.29 \%$ PMC). In the monoisodisomic plant (from progeny Mo54), two unpaired chromosomes of different sizes $(0.50 \pm 0.15$ in average per cell) were detected in $24 \%$ of PMCs. It was shown before that most of the pollen grains produced by PMCs with two univalents were deficient for chromosome 4 and nonfunctional [38]. Absence of frequent misdivision in the monosomics from Uzbek Cytogenetic Collection suggests monosome stability in the background of the line L-458 (genetic standard to development of monosomic lines in Uzbekistan). This monosome stability further is supported by the well-known phenomenon of coincidence of misdivision frequencies of centromers in monosomics with the frequency of iso-and telocentric chromosomes in their progenies. Moreover, this observation also implies the absence of the cotton monosomics for the chromosomes 12, 22 , and 25 . We cannot eliminate the influence of genetic background in this process. For example, in wheat genotype (Triticum aestivum L.), the role in univalent behavior was detected since the chromosome 5A misdivided more often in Chinese Spring background (39.7\%) than in other varieties. The genotype of Chinese Spring variety proved to be favorable to high misdivision rate, and more than half of misdivided univalents produced isochromosomes [39].

Transmission in the progenies of 12 translocation heterozygous monosomics revealed daughter monosomic plants in only 6 progenies. Moreover, in two of them (Mo9 and Mo22), the daughter monosomics had no quadrivalents, and one progeny (Mo61) had heterozygous translocation, whereas two monosomics from the Mo63 and Mo54 progenies were translocation homozygotes. There were quadrivalent associations in $\mathrm{F}_{1} \mathrm{BC}_{1}$ hybrids from the crosses with standard line L-458. This suggests a positive role of the chromosome interchanges in these monosomics because of a selective advantage of the gametes containing singlechromosome deficiencies and the interchange between two other chromosomes in hetero- and homozygous conditions, respectively.

According to a transmission study in 12 other monosomic families, disomic plants with desynaptic effect were detected due to desynapsis in parental plants and spontaneous desynaptic gene mutations in parental plants. Thus, analysis of monosomic progenies under field and greenhouse conditions provided daughter monosomic reproduction in 52 different families. However, the detection of other aberrations in 6 of them requires reanalysis of their progenies to isolate monosomics without any other karyotype disturbances.

The following selective behavior features were revealed in the cotton monosomics studied: karyotypic heterogeneity of progenies due to production of gametes with $n$ and $n-1$ chromosome set; various frequency of monosome transmission due to features of transmission of haplodeficient gametes and their viability; low univalent misdivision frequency observed in a few products of monosome divisions; high stability of univalents in monosomics in the inbred line L-458 background; high reproduction rate of other types of mutations in progenies, originated in initial plants independently from monosomy.

\section{Conclusions}

We developed a new set of cotton monosomic stocks through radioactive irradiation of single genotype of L458 cotton line. The results demonstrated detection of new unique desynaptic cotton plants in which progeny produced monosomics with high frequency. We observed the very rare occurrence of univalent misdivisions because of monosome stability in the unique genetic background. Our results demonstrate that light seed weight is not a universal marker for monosomy in cotton, and we detected possible univalent shifts in three monosomic progenies. Our observations with the development of reproductive organs of some monosomic plants suggested chromosome localization of genetic factors that control male gametophyte viability in the deficient chromosomes. Chromosomal identification of these new monosomic cotton stocks, using modern genetics methods (e.g., $[11,40-43])$, is a high priority for future comparative studies of our collection with existing monosomic collections of cotton. For this effort, we are crossing our monosomic stocks with well-defined tester translocation line sets that were obtained from cytogenetic collection of the USA (kindly provided by Dr. D. M. Stelly and Dr. S. Saha through USDA-Uzbekistan cotton germplasm exchange program). Subsequent generation of monosomic-translocation hybrids will be used to locate monosomes for specific cotton chromosomes through cytogenetic analyses. Alternatively, the creation of chromosome substitution lines through crossing of each of the new monosomics with $G$. barbadense genotype (Pima 3-79) is in progress. This will serve as a foundation to apply molecular markers (e.g., SSRs) for the identification of our monosomics in hybrids with chromosome substitutions for a given monosome. At the same time, our monosomic 
cotton collection with initial cytogenetic characteristics, developed using single genome background, should be useful germplasm for cotton researchers to use as materials for future breeding, genetic, cytogenetic, and molecular-genetic investigations of the cotton genome.

\section{Acknowledgments}

This work was partially supported by research Grants nos. 38/96, 28/98, 26/2000, and F.4.1.15 from the Committee for Science and Technology of the Republic of Uzbekistan. The authors thank Dr. Ian Dundas, University of Adelaide, Australia, and Dr. Masoud Sheidai, Shahid Beheshti University, Tehran, Iran for their critical reading of the paper and suggestions. They also thank Dr. Eric J. Devor, Iowa State University, USA, and Dr. Johnie N. Jenkins, USDA-ARS, Mississippi, USA, for their critical review and edition of the paper.

\section{References}

[1] National cotton Council, 2006, http://www.cotton.org/.

[2] Z. J. Chen, B. E. Scheffler, E. Dennis et al., "Toward sequencing cotton (Gossypium) genomes," Plant Physiology, vol. 145, no. 4, pp. 1303-1310, 2007.

[3] I. Y. Abdurakhmonov, S. Saha, J. N. Jenkins et al., "Linkage disequilibrium based association mapping of fiber quality traits in G. hirsutum L. variety germplasm," Genetica, vol. 136, no. 3, pp. 401-417, 2009.

[4] I. Y. Abdurakhmonov, "Exploiting genetic diversity," in Proceedings of the 4th World Cotton Research Conference, D. Ethridge, Ed., p. 2153, Lubbock, Tex, USA, 2007, Plenary Presentations and Papers.

[5] M. S. Brown and J. E. Endrizzi, "The origin, fertility and transmission of monosomic in Gossypium," American Journal of Botany, vol. 51, no. 1, pp. 108-115, 1964.

[6] J. E. Endrizzi and M. S. Brown, "Identification of monosomes for six chromosomes in Gossypium hirsutum," American Journal of Botany, vol. 51, no. 2, pp. 117-120, 1964.

[7] D. F. Galen and J. E. Endrizzi, "Induction of monosomes and mutations in cotton by gamma irradiation of pollen," Journal of Heredity, vol. 59, no. 6, pp. 343-346, 1968.

[8] J. E. Endrizzi and G. Ramsay, "Monosomes and telosomes for 18 of the 26 chromosomes of Gossypium hirsutum," Canadian Journal of Genetics and Cytology, vol. 21, no. 4, pp. 531-536, 1979.

[9] J. E. Endrizzi and G. Ramsay, "Identification of ten chromosome deficiencies of cotton: cytological identification of eight chromosomes and genetic analysis of chromosome deficiencies and marker genes," Journal of Heredity, vol. 71, no. 1, pp. 45-48, 1980.

[10] J. E. Endrizzi, E. L. Turcotte, and R. J. Kohel, "Genetics, cytology, and evolution of Gossypium," Advances in Genetics, vol. 23, pp. 271-375, 1985.

[11] Y. Ji, D. A. Raska, T. D. McKnight et al., "Use of meiotic FISH for identification of a new monosome in Gossypium hirsutum L," Genome, vol. 40, no. 1, pp. 34-40, 1997.

[12] D. A. Raska, D. M. Stelly, M. N. Islam-Faridi, and M. E. Woods, "Identification of a new monosome in cotton: chromosome 21," in Proceedings of the Beltwide Cotton Improvement Conference, p. 1072, National Cotton Council, New Orleans, La, USA, 2005.
[13] M. F. Sanamyan, J. E. Petlyakova, and D. A. Musaev, "The development and a cytogenetic study of monosomics of Gossypium hirsutum L," Biologia Plantarum, vol. 43, no. 2, pp. 193-197, 2000.

[14] M. F. Sanamyan and J. E. Petlyakova, "Cytogenetic analysis of cotton monosomics," Biologia Plantarum, vol. 45, no. 3, pp. 367-373, 2002.

[15] M. F. Sanamyan and E. M. Rakhmatullina, "Cytogenetic analysis of translocations in cotton," Plant Breeding, vol. 122, no. 6, pp. 511-516, 2003.

[16] M. F. Sanamyan, "Evaluation of the effect of pollen irradiation on karyotype variability in $\mathrm{M}_{1}$ cotton plants," Russian Journal of Genetics, vol. 39, no. 8, pp. 909-916, 2003.

[17] M. F. Sanamyan, "Evaluation of the effect of pollen irradiation on karyotype variability in $\mathrm{M}_{2}$ cotton plants," Russian Journal of Genetics, vol. 39, no. 7, pp. 791-798, 2003.

[18] R. M. Love, "Varietal differences in meiotic chromosome behaviour of Brasilian wheat," Agronomy Journal, vol. 43, pp. 72-76, 1951.

[19] R. E. Clausen and D. R. Cameron, "Inheritance in Nicotiana tabacum. 18. Monosomic analysis," Genetics, vol. 29, pp. 447477, 1944.

[20] E. R. Sears, "Cytogenetic studies with polyploid species of wheat-II. Additional chromosomal aberrations in Triticum vulgare," Genetics, vol. 29, no. 3, pp. 231-246, 1944. .

[21] E. R. Sears, “The aneuploids of common wheat," Research Bulletin/University of Missouri, Agricultural Experiment Station, no. 572, pp. 1-58, 1954.

[22] J. E. Endrizzi, "Use of haploids in Gossypium barbadense L. as a source of aneuploids," Current Science, no. 2, pp. 34-35, 1966.

[23] B. R. Tyagi and O. P. Dhawan, "Monosomics in Egyptian Henbane, Hyoscyamus muticus L. I. Meiotic behaviour and fertility," Cytologia, vol. 53, pp. 757-762, 1988.

[24] E. G. Zhirov, K. S. Bessarab, and M. A. Gubanova, "Genetical studies of partial desynapsis in common wheat," Genetica, vol. 9, no. 1, pp. 18-29, 1973 (Russian).

[25] M. S. Brown and M. Y. Menzel, "The genetic basis of chromosome pairing in Gossypium," in Proceedings of the International Congress of Genetics, vol. 9, p. 899, 1953.

[26] T. G. White and J. R. Endrizzi, "Tests for the association of marker loci with chromosomes in Gossypium hirsutum L. by the use of aneuploids," Genetics, vol. 51, pp. 605-612, 1965.

[27] G. A. Edwards, M. S. Brown, G. A. Niles, and S. A. Naqi, "Monosomics of cotton," Crop Science, vol. 20, no. 4, pp. 527528,1980 .

[28] E. L. Myles and J. E. Endrizzi, "Aneuploids induced by deficiencies of chromosome 9 and analysis of the time of nondisjunction in cotton," Genome, vol. 32, pp. 12-18, 1989.

[29] M. Y. Menzel and M. S. Brown, "Genetic lengths and break points in twelve chromosomes of Gossypium hirsutum involved in ten reciprocal translocations," Genetics, vol. 88, no. 3, pp. 541-558, 1978.

[30] G. A. Edwards, M. S. Brown, G. A. Niles, and S. A. Naqi, "The frequency of spontaneous and other monosomes at Beasley laboratory, 1946 to 1979," in Proceedings of the Beltwide Cotton Production Research Conference, pp. 103-106, 1980.

[31] J. W. Morrison and J. Unrau, "Frequency of micronuclei in pollen quartets of common wheat monosomics," Canadian Journal of Botany, vol. 30, pp. 371-378, 1952.

[32] G. S. Khush, Cytogenetics of aneuploids, Academic Press, London, UK, 1973. 
[33] D. Laskowska and A. Berbeć, "Cytology and fertility of viable hybrids of Nicotiana tabacum L. cv. TB-566 with N. alata Link et Otto," Journal of Applied Genetics, vol. 46, no. 1, pp. 11-18, 2005.

[34] C. R. Douglas, "Abortive pollen: a phenotypic marker of monosomics in Upland cotton, Gossypium hirsutum," Canadian Journal of Genetics and Cytology, vol. 10, pp. 913-915, 1968.

[35] C. R. Douglas, "Relationship of seed weight to the cytotype of monosomic progeny in cotton," Crop Science, vol. 12, pp. 530531, 1972.

[36] M. A. Khrabrova and O. I. Maystrenko, "Monosomic genetic analysis of corn seed protein content and its weight in Diamant 2 common wheat," Genetica, vol. 16, no. 8, pp. 1425-1434, 1980 (Russian).

[37] M. S. Brown, "The division of univalent chromosomes in Gossypium," American Journal of Botany, vol. 45, no. 1, pp. 2432, 1958.

[38] J. E. Endrizzi and R. Bray, "Cytogenetics of disomics, monotelo- and monoisodisomics and ml1st1 mutants of chromosome 4 of cotton," Genetics, vol. 9, pp. 979-988, 1980.

[39] E. R. Sears, "Misdivision of univalents in common wheat," Chromosoma, vol. 4, pp. 535-550, 1952.

[40] K. Wang, Z. Yang, C. Shu et al., "Higher axial-resolution and sensitivity pachytene fluorescence in situ hybridization protocol in tetraploid cotton," Chromosome Research, vol. 17, no. 8, pp. 1041-1050, 2009.

[41] K. Wang, B. Guan, W. Guo et al., "Completely distinguishing individual A-genome chromosomes and their karyotyping analysis by multiple bacterial artificial chromosomefluorescence in situ hybridization," Genetics, vol. 178, no. 2, pp. 1117-1122, 2008.

[42] K. Wang, W. Guo, and T. Zhang, "Development of one set of chromosome-specific microsatellite-containing BACs and their physical mapping in Gossypium hirsutum L," Theoretical and Applied Genetics, vol. 115, no. 5, pp. 675-682, 2007.

[43] K. Wang, W. Guo, and T. Zhang, "Detection and mapping of homologous and homoeologous segments in homoeologous groups of allotetraploid cotton by BAC-FISH," BMC Genomics, vol. 8, article 178, 2007. 

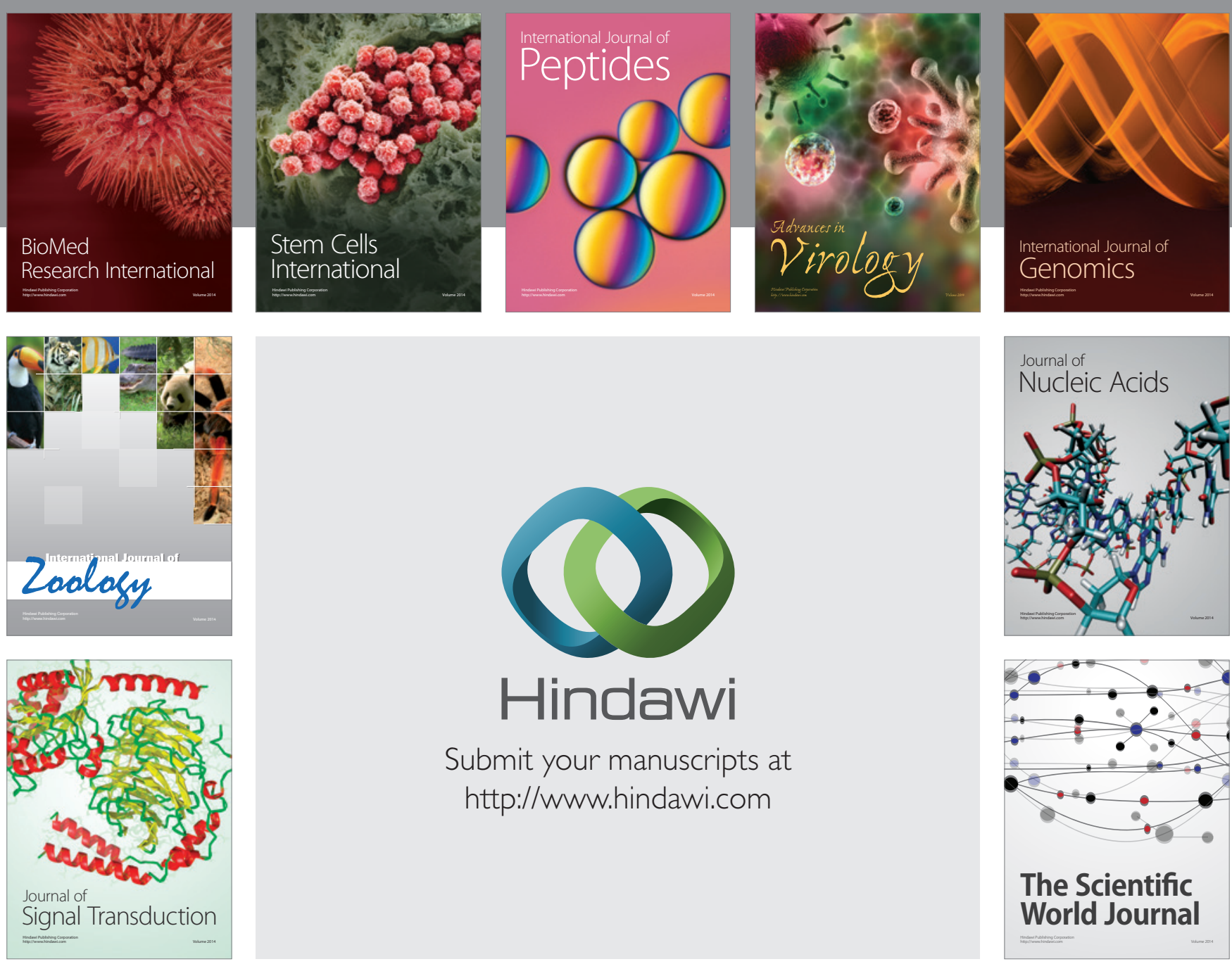

Submit your manuscripts at

http://www.hindawi.com
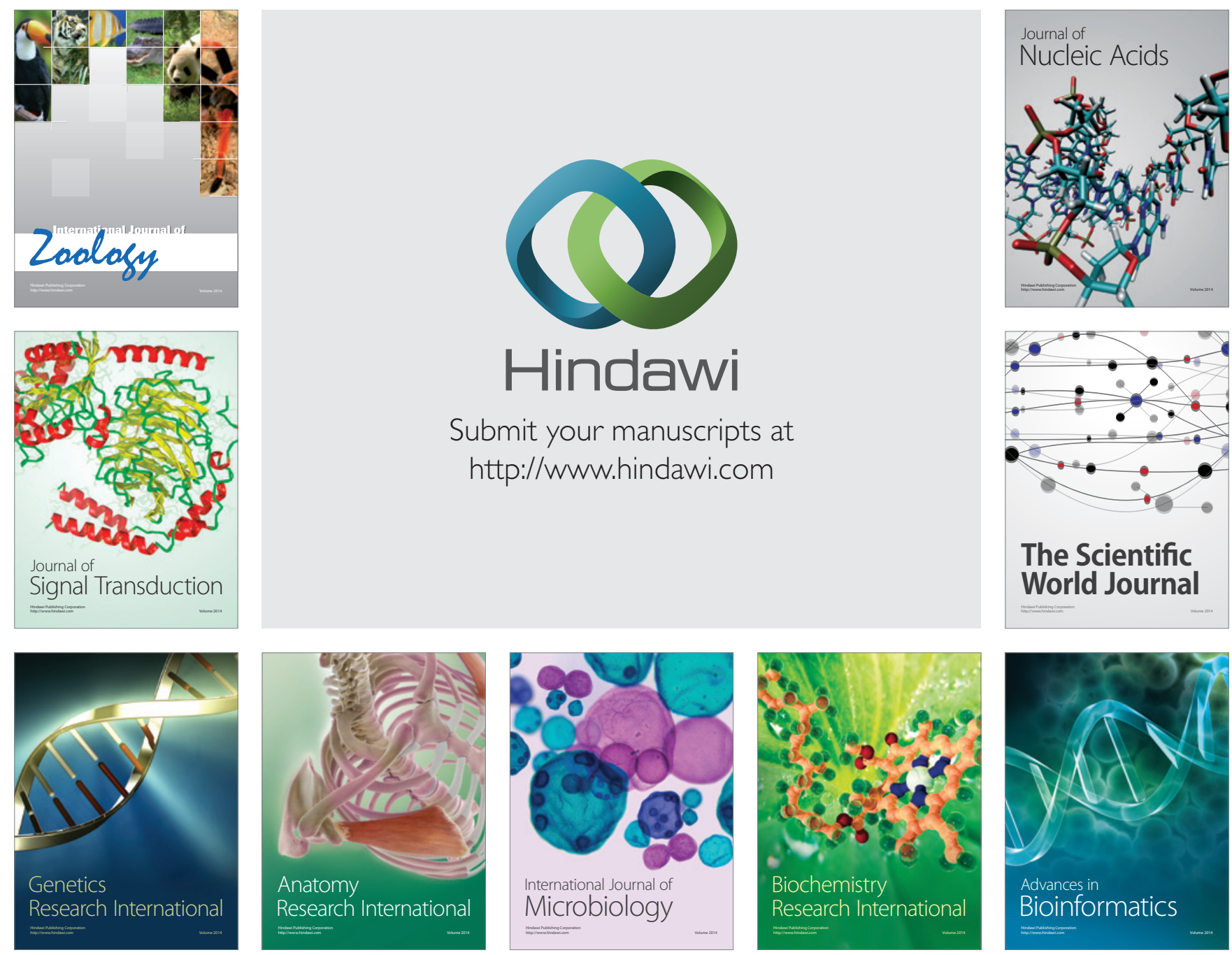

The Scientific World Journal
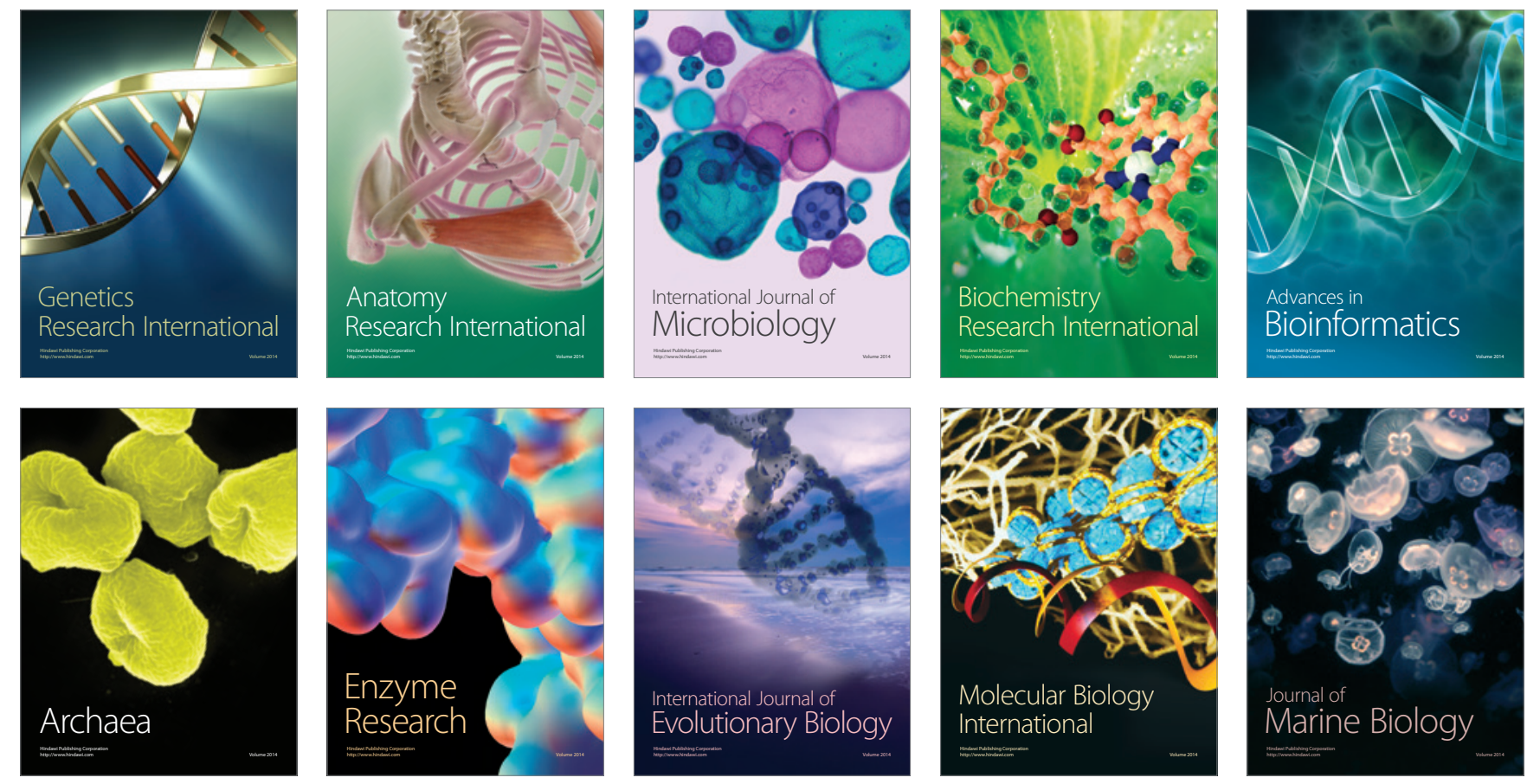